\title{
1 Hyperglycaemic preterm babies have sex differences in insulin secretion
}

3 Jennifer L. Dickson ${ }^{\mathrm{a}}$, J. Geoffrey Chase ${ }^{\mathrm{a}}$, Christopher G. Pretty ${ }^{\mathrm{a}}$, Cameron A. Gunn ${ }^{\mathrm{a}}$, Jane 4 Alsweiler ${ }^{\mathrm{b}, \mathrm{c}}$

5

$6 \quad{ }^{a}$ Department of Mechanical Engineering, University of Canterbury, Christchurch, New Zealand

$7 \quad{ }^{b}$ Department of Paediatrics: Child and Youth Health, Auckland, New Zealand

$8 \quad{ }^{\mathrm{c}}$ Liggins Institute, University of Auckland, Auckland, New Zealand

9

10

Work conducted: Liggins Institute, University of Auckland, Auckland, New Zealand

Short title: Insulin secretion in preterm babies

Word count: 2,615

Postal address of corresponding author:

Jane M Alsweiler

Department of Paediatrics,

16 Faculty of Medical and Health Sciences,

17 University of Auckland,

18 Private Bag 92019,

19 Auckland 1142,

20 New Zealand

21 Email: j.alsweiler@auckland.ac.nz 
24 Key words: Preterm, hyperglycaemia, insulin secretion, sexual dimorphism

Abstract

Background: Hyperglycaemia is a common complication of prematurity and is associated with neonatal mortality and morbidity, yet the aetiology is incompletely understood. C-peptide has been used in adults to estimate endogenous insulin secretion due to its simple clearance kinetics.

Objective: To determine insulin secretion calculated from plasma C-peptide concentrations in hyperglycaemic preterm babies.

Methods: A retrospective analysis of a cohort of 41 very preterm babies (median gestational age, weeks: 27.2 (26.2-28.7)) enrolled in a randomised controlled trial of tight glycaemic control when they developed hyperglycaemia ( 2 consecutive blood glucose concentrations $(\mathrm{BGC})>8.5 \mathrm{mmol} . \mathrm{L}^{-1}$ ). Insulin secretion was determined using a steady state analysis of a 2 compartment C-peptide kinetic model.

Results: BGC, plasma insulin concentration, plasma C-peptide concentrations and insulin secretion were higher at randomisation than 1-2 weeks following randomisation $(\mathrm{p} \leq 0.02)$. Insulin secretion was higher in girls (11.7 (5.3-18.7) vs. $\left.4.7(2.1-8.3) \mathrm{mU} \cdot \mathrm{L}^{-1} \cdot \mathrm{kg}^{-1} \cdot \mathrm{min}^{-1}, \mathrm{p}<0.005\right)$ with no difference in clinical characteristics, BGC, plasma insulin concentration, or nutrition between the sexes ( $>0.25)$. Insulin secretion was lower in samples taken during exogenous insulin delivery (3.7 (1.8 - 6.9) vs. 9.8 (4.7 - 17.8) $\left.\mathrm{mU} \cdot \mathrm{L}^{-1} \cdot \mathrm{kg}^{-1} \cdot \mathrm{min}^{-1}, \mathrm{p}=0.02\right)$.

Conclusions: Insulin secretion was higher when babies had higher BGC, indicating endogenous insulin secretion is sensitive to BGC. Girls had higher insulin secretion, at similar blood glucose and plasma insulin concentrations, than boys.

\section{Introduction}

Elevated blood glucose concentrations (BGC, hyperglycaemia) are a common complication of prematurity, affecting up to $80 \%$ of extremely low birth weight babies.[1] Hyperglycaemia has been associated with neonatal morbidity and mortality, but it is unknown if this is a causal relationship.[2,3] Several studies have suggested that the cause of neonatal hyperglycaemia is 
multifactorial: defective insulin production and relative insulin resistance;[4] incomplete suppression of endogenous glucose production,[5] and stress.[6] However, there are few data on the glycaemic regulation system in preterm babies.

Insulin secretion in preterm babies, determined by plasma insulin concentrations, is responsive to systemic glucose and amino acids.[7] In adults, insulin secretion is increased by incretins, and suppressed by catecholamines and cortisol. Insulin is cleared by both the kidneys and the liver in a highly variable manner, as well as being cleared in peripheral tissues, making plasma insulin concentrations an inaccurate measure of insulin secretion. Pancreatic insulin secretion has been estimated in adults using models of C-peptide kinetics.[8] C-peptide is secreted in equimolar quantities with insulin, but is only cleared by the kidney. Therefore, the relatively simple kinetics of C-peptide provide a more accurate method of estimating insulin secretion. [8]

This aim of this study was to determine insulin secretion, calculated retrospectively from plasma CPeptide concentrations, in preterm babies enrolled in a randomised controlled trial of tight glycaemic control[9] to determine predictors for insulin secretion in hyperglycaemic preterm babies.

\section{Methods}

Plasma samples were collected from 88 preterm babies during a prospective, randomised trial of tight glycaemic control of preterm babies (The HINT trial,[9] Australian Clinical Trials Registry 12606000270516, ethics approval from Northern X ethics committee, written informed consent was obtained from a parent of each child). This trial compared tight glycaemic control (TGC) using insulin to maintain the BGC 4-6 mmol. $\mathrm{L}^{-1}$ in hyperglycaemic preterm babies, with standard care (control group), at the National Women's Health NICU, New Zealand.[9] Babies were eligible for enrolment if they were born at $<30$ weeks' gestational age (GA), or birth weight $<1500 \mathrm{~g}$, and had become hyperglycaemic (two consecutive BGC measures $>8.5 \mathrm{mmol}^{-\mathrm{L}^{-1}}$ at least 4 hours apart). Babies were randomised when they became hyperglycaemic (usually 4-5 days postnatal age). Parenteral nutrition was commenced within the first day after birth and enteral feeds with small amounts of breastmilk were usually started in the first one to two days after birth. Small for GA was defined as less than the 


$$
\begin{gathered}
\frac{d C}{d t}=S-\left(k_{1}+k_{3}\right) C+k_{2} Y \\
\frac{d Y}{d t}=k_{1} C-k_{2} Y
\end{gathered}
$$

92 Where $C$ is the amount of C-peptide in the central compartment of plasma (and tissues in rapid equilibrium with the plasma), and $Y$ is the amount of C-peptide in the peripheral extra vascular compartment. C-peptide (and insulin) is secreted into the central compartment at rate $S$. Transport of C-peptide from the central to the peripheral compartment, and back, is described by $k_{1}$ and $k_{2}$. Irreversible renal clearance of C-peptide from the central compartment via the kidney is modelled by $k_{3 .}$.[8] 
A steady-state assumption can be made to enable deconvolution of the insulin secretion rate from measured C-peptide concentrations. Under this steady-state assumption, it follows from Equation 2 that the rate of C-peptide entering and leaving the peripheral compartment must be equal. Hence, substituting this equality into Equation 1 and rearranging yields:

$$
S=k_{3} C
$$

Since insulin is secreted in equimolar quantities with C-peptide, under steady state conditions the rate of secretion of insulin is directly proportional to the measured concentration of C-peptide in the central compartment.

\section{Statistical Analysis}

Results are presented as median (IQR) or number (\%) as appropriate. Non parametric data were log transformed to approximate normal distributions and compared using Student's $t$ test. The Lilliefors test was used to assess the results of the transformations. P-values $<0.05$ were considered statistically significant.

\section{Results}

Of the 88 babies recruited to the trial, 41 were of GA<32 weeks' and had sufficient plasma from 1 or more of the samples for further analysis, totalling 54 samples taken at a median of 7 days after randomisation. Of these 41 babies, 20 were from the tight glycaemic control group, contributing 25 samples. Median birthweight was $839 \mathrm{~g}$ and gestation was 27 weeks (Tables 1 and 2).

BGC, plasma insulin, plasma C-peptide concentrations and insulin secretion decreased following randomisation (Figure). There was no difference between TGC and control groups in BGC (5.8[4.8$11.0]$ vs. $8.0[5.3-10.6]$ mmol. $\left.\mathrm{L}^{-1}, \mathrm{p}=0.27\right)$, plasma insulin concentration $(14.3[8.0-27.6]$ vs $14.3[8.2-$ 27.6] mU.L $\left.\mathrm{L}^{-1}, \mathrm{p}=0.75\right)$, plasma IGF-1 (5.8[3.5-8.7] vs 7.1[3.9-9.3] ng.mL $\left.{ }^{-1}, \mathrm{p}=0.83\right)$, C-peptide concentration $\left(0.51[0.24-1.19]\right.$ vs $\left.0.98[0.42-1.56] \mathrm{mmol}^{-1} \mathrm{~L}^{-1}, \mathrm{p}=0.09\right)$, or insulin secretion $(6.0[3.1$ 11.8] vs 11.1[3.9-18.1] $\left.\mathrm{mU} \cdot \mathrm{L}^{-1} \cdot \mathrm{kg}^{-1} \cdot \mathrm{min}^{-1}, \mathrm{p}=0.16\right)$. There were no differences in BGC, plasma insulin concentrations, and insulin secretion with ethnicity $(\mathrm{p} \geq 0.29)$. There was not a statistically significant 
correlation between insulin secretion and CRIB 2 score $\left(\mathrm{r}^{2}=0.04, \mathrm{p}=0.33\right)$ or plasma cortisol concentration at randomisation $\left(\mathrm{r}^{2}=0.05, \mathrm{p}=0.30\right)$.

Of 54 samples, 41 were from singleton births. More babies from non-singleton birth were male (70\% vs. 39\%) but were similar in GA, weight, postnatal age and CRIB 2 score than babies from singleton birth $(\mathrm{p}>=0.69)$. The BGC was higher in the singleton group (8.6[5.6-11.1] vs. 5.5[4.8-7.5] mmol. $\mathrm{L}^{-1}$, $\mathrm{p}=0.03$ ), but insulin secretion was not significantly different in babies from singleton compared with non-singleton births $\left(9.1[3.7-19.4]\right.$ vs. $\left.5.1[3.2-10.2] \mathrm{mU} \cdot \mathrm{L}^{-1} \cdot \mathrm{kg}^{-1} \cdot \mathrm{min}^{-1}, \mathrm{p}=0.28\right)$.

Insulin secretion was higher in girls (Table 3). This difference was seen both at randomisation (18.0 [13.3-27.1] vs. $\left.6.7[3.5-9.4] \mathrm{mU} \cdot \mathrm{L}^{-1} \cdot \mathrm{kg}^{-1} \cdot \mathrm{min}^{-1}, \mathrm{p}=0.01\right)$ and post randomisation $(8.2$ [4.8-13.0] vs. 3.6 $\left.[1.2-7.6] \mathrm{mU} \cdot \mathrm{L}^{-1} \cdot \mathrm{kg}^{-1} \cdot \mathrm{min}^{-1}, \mathrm{p}=0.03\right)$. There was no significant difference in insulin secretion between TGC and control groups for either sex (girls: $12.5[4.9-20.4]$ vs. $11.7[8.0-17.4] \mathrm{mU} \cdot \mathrm{L}^{-1} \cdot \mathrm{kg}^{-1} \cdot \mathrm{min}^{-1}$, $\mathrm{p}=0.81$; boys: $4.7[1.8-7.3]$ vs. 6.5 [2.2-11.5] $\left.\mathrm{mU} \cdot \mathrm{L}^{-1} \cdot \mathrm{kg}^{-1} \cdot \mathrm{min}^{-1}, \mathrm{p}=0.48\right)$. Clinical characteristics; BGC or plasma insulin concentrations; nutrition amount or delivery method were not different among the sexes (Table 3).

Insulin secretion was lower at the time of samples taken during an insulin infusion $(n=13)$ than when not on insulin infusion (3.7 [1.8-6.9] vs. 9.8[4.7-17.8] $\left.\mathrm{mU}^{\mathrm{kg}} \mathrm{kg}^{-1} \cdot \mathrm{min}^{-1}, \mathrm{p}=0.02\right)$ with no statistically significant effect on BGC (insulin infusion; 6.9[5.4-9.5] vs. not on insulin; 7.6[5.0-11.1] mmol.. $\mathrm{L}^{-1}$, $\mathrm{p}=0.46$ ) or plasma insulin concentration (insulin infusion; $19.9[9.2-26.7]$ vs. not on insulin; 13.2[6.627.1]mU.L $\left.{ }^{-1}, \mathrm{p}=0.25\right)$.

At the time of the sample 47 infants $(87 \%)$ received more than $80 \%$ of their total glucose via one feeding method: parenteral or enteral. 20 samples were from babies that received more than $80 \%$ of their total glucose delivery from enteral feeds (15.0[13.6-16.7] g.day ${ }^{-1}$ lactose), and 27 were from babies that were primarily receiving parenteral nutrition (8.3[5.9-9.8] g.day ${ }^{-1}$ glucose). The primarily enterally fed group were older at the time of the sample (17.5[15.8-19.3] vs. 5[3-7.5] days, $\mathrm{p}<0.005)$, and had a lower BGC (5.8[4.4-8.0] vs. 9.6[6.1-12.0] mmol. $\left.\mathrm{L}^{-1}, \mathrm{p}=0.002\right)$. Protein intake on the day of sampling was greater in babies on enteral feeds (3.9[3.4-4.0] vs. 2.7[2.2-2.9] g, $\mathrm{p}<0.005)$. There was 
no statistically significant difference in insulin secretion between babies primarily receiving enteral or parenteral nutrition $\left(8.3[5.3-15.1]\right.$ vs. $\left.8.2[2.5-17.9] \mathrm{mU} \cdot \mathrm{L}^{-1} \cdot \mathrm{kg}^{-1} \cdot \mathrm{min}^{-1}, \mathrm{p}=0.59\right)$. In the parenterally fed group insulin secretion was higher in girls (14/27 samples), (16.1[4.6-24.5] vs. 7.6[2.4-10.3] mU.L' ${ }^{1} \cdot \mathrm{kg}^{-1} \cdot \mathrm{min}^{-1}, \mathrm{p}=0.03$ ), with no sex difference in BGC, dextrose or protein intake (data not shown).

\section{Discussion}

This study determined insulin secretion, calculated from plasma C-Peptide concentrations, in hyperglycaemic preterm babies randomised to tight glycaemic control or standard care. Insulin secretion in girls was more than double that in boys, despite similar clinical characteristics, plasma insulin and blood glucose concentrations, and no sex difference in the incidence of neonatal hyperglycaemia in babies eligible for the HINT trial.[9] The effect of sex on insulin secretion, as measured by C-peptide concentrations, has not been reported previously in preterm babies.[4] The relatively higher C-peptide and insulin secretion in females could reflect lower insulin sensitivity compared to males, or impaired renal clearance of C-peptide. We were unable to calculate the glomerular filtration rate (GFR) in these preterm babies, However, GFR has not been observed to be different between the sexes in preterm babies previously.[11] Several previous studies have also demonstrated sexual dimorphism in cardiovascular risk factors, such as blood pressure and heart rate variability, in preterm animals and babies.[12,13]

This study used C-peptide measurements, data that relatively few studies have reported for this population. $[4,14]$ C-peptide concentration is a more accurate indicator of insulin secretion than plasma insulin concentration due to its simple clearance kinetics. In particular, C-peptide is only cleared through the kidney, in contrast to the multiple clearance paths of insulin.[8] Calculating the insulin secretion rate from C-Peptide concentrations deconvolves insulin secretion from insulin clearance and exogenous insulin inputs using a clinically well accepted approach.[8] It is more accurate than peak plasma insulin or area under the curve based methods, which examine net insulin turnover subject to a range of clearance routes. 
174 Differences in insulin concentrations and insulin sensitivity between the sexes have previously been 175 observed during infancy and later in life. Plasma insulin and IGF-1 concentrations are higher in girls 176 born at term than boys.[15] Women have been shown to have higher insulin sensitivity,[16] and post177 pubertal, pre-menopausal women are less likely than men to develop diabetes; a trend that reverses after menopause.[17] Potentially, the sex differences in insulin secretion seen in our study could be due to sex hormones, as oestrogen protects against beta cell apoptosis in mice[18] and oestrogen replacement therapy reduces the incidence of type 2 diabetes in post-menopausal women.[19]

Preterm birth is associated with higher mortality, and poorer neurodevelopmental outcome in boys than girls.[20] Animal studies have shown that in utero interventions, such as alterations of maternal diet, result in sexual dimorphism of cardiovascular risk factors, such as insulin resistance and raised blood pressure.[21] Recent studies have also shown sexual dimorphism in cardiovascular risk factors after preterm birth in both animal models and human studies.[12,13,22] Girls may respond differently to antenatal glucocorticoids, or preterm birth, than boys. Insulin sensitivity is reduced in children born preterm[23] and adults[24] exposed to antenatal glucocorticoids. Placental 11ß-hydroxysteroid dehydrogenase-2 activity following antenatal betamethasone is greater in girls than boys,[25] which may reduce the ability of betamethasone to increase insulin sensitivity in girls. As nearly all babies in this study were exposed to antenatal glucocorticoids it was not possible to analyse the effect of antenatal glucocorticoids on insulin secretion.

Plasma insulin and C-peptide concentrations were also higher at randomisation, when all the babies were hyperglycaemic, suggesting that pancreatic insulin secretion in preterm babies is sensitive to BGC. Plasma insulin and C-peptide concentrations have previously been shown to decrease after insulin therapy to restore euglycaemia in a group of extremely preterm hyperglycaemic babies,[4] with similar C-peptide concentrations to the current study. In this study, insulin secretion was lower in babies receiving insulin infusion, suggesting suppression of endogenous secretion. However, there were insufficient samples to determine conclusively the effect of intravenous insulin therapy on endogenous insulin secretion. 
There was no statistically significant difference in insulin secretion between babies fed enterally or

201 parenterally, indicating that enteral feeds may not increase insulin secretion in preterm babies.

202 Previous studies have observed higher fasting and post-feed concentrations of glucagon-like peptide-

203 1, which has an incretin effect, in term and preterm babies,[26] but there are no data available on the effect of this on insulin secretion in preterm babies. In this study, we were unable to further investigate the effect of nutrition on insulin secretion in preterm babies due to the comparison of glucose (parenteral) and lactose (enteral), and the availability of daily totals of these sugars only. Moreover, babies receiving predominantly enteral feeds were more likely to be older than babies on parenteral feed. Insulin secretion is known to be enhanced or suppressed in adults by multiple variables, including BGC, nutritional intake and stress. Our finding of higher insulin secretion with higher BGC reflects other literature in preterm babies.[5] However, we did not find an association between insulin secretion and protein or total dextrose intake; plasma cortisol concentration, or route of nutrition administration. This lack of association may be due to the retrospective nature of this study, or may represent differences between preterm babies and adults which require further research.

214 The major assumption required for the calculation of insulin secretion is that of steady state kinetics, an assumption which is considered necessary due to sampling limitations, as the small blood volume of extremely preterm babies limits the number of C-peptide measurements, and is reasonable in babies fed via parenteral infusions that do not tend to change dramatically from hour to hour. This assumption is perhaps less valid in enterally fed infants. However, when the analysis was repeated with samples only from infants who were mainly parenterally fed, the main study outcomes were unchanged. The study is also limited by its retrospective nature. However, given the scarcity of data in this extremely fragile cohort, it provides some insights into hyperglycaemic preterm infants otherwise not available.

Girls had higher insulin secretion at similar blood glucose and plasma insulin concentrations to male babies. This may reflect a difference in insulin sensitivity in hyperglycaemic preterm girls. Therefore, interventions to prevent or treat neonatal hyperglycaemia may not be equally effective in girls and boys. 
228 1. Beardsall K, Vanhaesebrouck S, Ogilvy-Stuart AL, Vanhole C, Palmer CR, Ong K,

229 vanWeissenbruch M, Midgley P, Thompson M, Thio M, Cornette L, Ossuetta I, Iglesias I, Theyskens C, de Jong M, Gill B, Ahluwalia JS, de Zegher F, Dunger DB. Prevalence and determinants of hyperglycemia in very low birth weight infants: cohort analyses of the NIRTURE study. J. Pediatr,. 2010;157(5):715-9.e3.

2. Alsweiler JM, Harding JE, Bloomfield F. Neonatal hyperglycaemia increases mortality and morbidity in preterm lambs. Neonatology. 2013;103(2):83-90.

3. Hays SP, Smith EOB, Sunehag AL. Hyperglycemia is a risk factor for early death and morbidity in extremely low birth-weight infants. Pediatrics. 2006;118(5):1811-8.

4. Mitanchez-Mokhtari D, Lahlou N, Kieffer F, Magny J-F, Roger M, Voyer M. Both relative insulin resistance and defective islet $\{$ beta\}-cell processing of proinsulin are responsible for transient hyperglycemia in extremely preterm infants. Pediatrics. 2004;113(3):537-41.

5. Sunehag A, Gustafsson J, Ewald U. Very immature infants ( $<$ or $=30 \mathrm{Wk}$ ) respond to glucose infusion with incomplete suppression of glucose produciton. Pediatr. Res. 1994;36(4):550-5. 6. Louik C, Mitchell AA, Epstein MF, Shapiro S. Risk factors for neonatal hyperglycemia associated with 10\% dextrose infusion. Am. J. Dis. Child. 1985;139(8):783-6.

7. Grasso S, Messina A, Distefano G, Vigo R, Reitano G. Insulin secretion in the premature infant. Response to glucose and amino acids. Diabetes. 1973;22(5):349-53.

8. Van Cauter E, Mestrez F, Sturis J, Polonsky KS. Estimation of insulin secretion rates from Cpeptide levels. Comparison of individual and standard kinetic parameters for C-peptide clearance. Diabetes. 1992;41(3):368-77.

9. Alsweiler JM, Harding JE, Bloomfield FH. Tight glycemic control with insulin in hyperglycemic preterm babies: a randomized controlled trial. Pediatrics. 2012;129(4):639-47.

10. Beeby PJ, Bhutap T, Taylor LK. New South Wales population-based birthweight percentile charts. J. Paediatr. Child Health. 1996;32(6):512-8.

11. Rhodin MM, Anderson BJ, Peters AM, Coulthard MG, Wilkins B, Cole M, Chatelut E, Grubb A, Veal GJ, Keir MJ, Holford NH. Human renal function maturation: a quantitative description using weight and postmenstrual age. Pediatr Nephrol. 2009;24(1):67-76.

12. Berry MJ, Jaquiery AL, Oliver MH, Harding JE, FH B. Preterm birth has sex-specific effects on autonomic modulation of heart rate variability in adult sheep. PLOS ONE. 2013;8(12):e86568.

13. Feldt K, Raikkonen K, Eriksson JG, Andersson S, Osmond C, Barker DJP, Phillips DIW, Kajantie E. Cardiovascular reactivity to psychological stressors in late adulthood is predicted by gestational age at birth. J. Hum. Hypertens. 2007;21(5):401-10.

14. Tsubahara M, Shoji H, Mori M, Matsunaga N, Ikeno M, Hisata K, Okumara A, Shimizu T. Glucose metabolism soon after birth in very premature infants with small- and appropriate-for gestational-age birth weights. Early Hum. Dev. 2012;88(9):735-8.

15. Ibáñez L, Sebastiani G, Lopez-Bermejo A, Díaz M, Gómez-Roig MD, de Zegher F. Gender specificity of body adiposity and circulating adiponectin, visfatin, insulin, and insulin growth factor-I at term birth: relation to prenatal growth. J. Clin. Endocrinol. Metab. 2008;93(7):2774-8.

16. Mathai S, Cutfield WS, Derraik JG, Dalziel SR, Harding JE, Robinson E, Biggs J, Jefferies C, Hofman PL. Insulin sensitivity and beta-cell function in adults born preterm and their children. Diabetes. 2012;61(10):2479-83.

17. Macrae D, Grieve R, Allen E, Sadique Z, Morris K, Pappachan J, Parslow R, Tasker RC, Elbourne D. A randomized trial of hyperglycemic control in pediatric intensive care. N. Engl. J. Med. 2014;370(2):107-18.

18. Le May C, Chu K, Hu M, Ortega CS, Simpson ER, Korach KS, Tsai M-J, Mauvais-Jarvis F. Estrogens protect pancreatic beta-cells from apoptosis and prevent insulin-deficient diabetes mellitus in mice. Proc. Natl. Acad. Sci. U.S.A. 2006;103(24):9232-7.

19. Margolis KL, Bonds DE, Rodabough RJ, Tinker L, Phillips LS, Allen C, Bassford T, Burke G, Torrens J, Howard BV, Women's Health Initiative I. Effect of oestrogen plus progestin on the 
incidence of diabetes in postmenopausal women: results from the Women's Health Initiative

279 Hormone Trial. Diabetologia. 2004;47(7):1175-87.

$28020 . \quad$ Moore T, Hennessy EM, Myles J, Johnson SJ, Draper ES, Costeloe KL, Marlow N. Neurological and developmental outcome in extremely preterm children born in England in 1995 and 2006: the EPICure studies. BMJ. 2012;345(e7961). 21. Aiken C, Ozanne S. Sex differences in developmental programming models. Reproduction. 2013;145:1-13.

22. Kaseva N, Wehkalampi K, Pyhala R, Moltchanova E, Feldt K, Pesonen A-K, Heinonen K, Hovi $P$, Jarvenpaa A-L, Andersson S, Eriksson JG, Raikkonen K, Kajantie E. Blunted hypothalamic-pituitaryadrenal axis and insulin response to psychosocial stress in young adults born preterm at very low birth weight. Clin. Endocrinol. 2014;80(1):101-6. 23. Hofman PL, Regan F, Jackson WE, Jefferies C, Knight DB, Robinson EM, Cutfield WS. Premature birth and later insulin resistance. N. Engl. J. Med. 2004;351(21):2179-86. 24. Dalziel SR, Walker NK, Parag V, Mantell C, Rea HH, Rodgers A, Harding JE. Cardiovascular risk factors after antenatal exposure to betamethasone: 30-year follow-up of a randomised controlled trial. Lancet. 2005;365(9474):1856-62. dehydrogenase 2 activity and early postnatal clinical course following antenatal betamethasone. Am J Physiol Regul Integr Comp Physiol. 2009;297(2):R510-4. glucagon-like peptide 1 (GLP-1) concentrations in the neonatal period. Eur. J. Endocrinol. 